\title{
A disaster severity assessment decision support tool for reducing the risk of failure in response operations
}

\author{
S. Hasani, R. El-Haddadeh \& E. Aktas \\ Business School, Brunel University, UK
}

\begin{abstract}
After a disaster strikes, the disaster severity needs to be estimated in order to provide an adequate humanitarian response. The decision makers need to decide quickly about the requisite supplies and bespoke teams based on the scale and nature of the disruption. The failure of the severity assessment may impose risk to the success of the response operations, leading to the loss of lives at worst. The existing severity assessment tools employ various criteria such as intensity, frequency, vulnerability and capability. However a framework which differentiates between the impact of disasters on communities with different coping capabilities, is missing. For example, an equally intense earthquake affects Japan differently from Haiti, due to the difference in the coping capabilities of the two nations. To that end this paper investigates the records of previous disasters to provide a holistic Disaster Severity Assessment (DSA) tool. This decision support tool accommodates physical and socio-economic impacts of the disaster on the affected population. The assessment is based on six criteria including impact time, fatality, casualty, relative financial damage, Human Development Index (HDI) and Disaster Risk Index (DRI). The resulting decision support tool may be used to diagnose the severity of the disaster immediately after it strikes. It also is capable of accommodating the imprecise data by the means of a fuzzy classification system. This characteristic allows the decision maker to draw a realistic picture of the disaster response required based on the affected population capabilities and reduce the risk of failure in disaster response operations.
\end{abstract}

Keywords: disaster response operations, severity assessment, disaster risk management, risk reduction, decision support, fuzzy classification. 


\section{Introduction}

Disaster as a physical disruption leaves the community incapable of coping with the impacts of the disaster. Therefore the timely supply of adequate aid and supplies during the response operation would save lives. Conversely the risk of failure of the disaster response operation may be increased by inaccurate assessment of the disaster severity.

The present paper suggests that a decision support tool drawn upon the existing data from previous disasters could be used as a guideline for the severity assessment of future disasters with similar characteristics. This scenario-based decision support technique would assist in estimating the impact of the disaster on the affected community in the early stages of the disaster, and provide an accurate estimation of the required aid at an early stage. The impact of disasters has been the subject of a number of studies providing a scalable framework for classifying any given disaster's disruption effect. These frameworks are based on, amongst others: intensity, affected population, temporal and geographical dispersion [1-3]. Other approaches have been developed to take into account the social and cultural variables [4-6] as well as the socio-economic variables such as coping capability, vulnerability, social preparedness, human development indicator, disaster risk index, exposure, resourcefulness and demand/supply capability of the affected communities [7-13]. The significance of these approaches is to differentiate between the actual impacts of the disaster on various communities. For example an intense flood, which barely puts lives and infrastructure in danger, due to its occurrence in a remote area might not require a humanitarian response [8]. Also two disasters with a similar disruption magnitude could have a low impact in a community with more coping capabilities such as Japan, whilst it might create a catastrophic impact on Haiti with a lower level of coping capabilities. One problem that decision makers are facing is that despite the existence of the appropriate measures in the literature, a holistic severity assessment tool, which differentiates between the various scenarios of disasters, is yet to be developed. Another problem that decision makers are facing is that due to the time pressures during a disaster, most of the data remains un-obtainable, unreliable or imprecise. Therefore the decision tool needs to be based on existing or obtainable data, and have the capability to accommodate imprecise values. To that end the current study aims to design a disaster severity assessment tool based on previous experience, which is quick, easy to use and capable of working with existing data. It also is required to accommodate the imprecise values inherited in the uncertain disaster situation.

\section{Disaster Severity Assessment (DSA method)}

The first step is to develop a method for the classification of previous major disasters. The aim is to identify a pattern for disaster severity. In this step the secondary data from four various sources is obtained. Primarily the prominent natural disasters occurring after 1980 mentioned in the encyclopedia of disasters by Gunn [14] have been analysed. The results were compared to the 
costliest/deadliest disasters in NatCatSERVICE [15] provided by 'Munich Reinsurance Company' and containing 26,000 natural disasters since 1979. This data was then compared to the EM-DAT database [16] published by the 'Centre for Research on the Epidemiology of Disasters' and is based on 17,000 natural and technological disasters since 1900 . Finally the results were compared to the DesInventar project [17] and resulted in identification of 61 disasters as the data source for the present paper (table 1).

Table 1: An example of the data source for the present paper.

\begin{tabular}{|c|c|c|c|c|c|}
\hline Year & Disaster type & Origin & Fatalities & Affected people & Overall Loss \\
\hline 1983 & Earthquake & USA & 1545 & 31 & Not specified \\
\hline 1985 & Earthquake & Mexico & 9500 & 2130204 & 4104 \\
\hline 1988 & Earthquake & Armenia & \multicolumn{3}{|c|}{ Non-existent in the data base } \\
\hline 1989 & Earthquake & USA & 62 & 3757 & 5600 \\
\hline 1990 & Earthquake & Iran & 26796 & 267628 & 500 \\
\hline 1994 & Earthquake & USA & 60 & 27000 & 30000 \\
\hline 1995 & Earthquake & Japan & 5297 & 541636 & 100000 \\
\hline 1999 & Earthquake & Taiwan & 2264 & 108664 & 14100 \\
\hline 1999 & Earthquake & Turkey & 17127 & 1358953 & 20000 \\
\hline 2001 & Earthquake & India & 20005 & 6321812 & 2623 \\
\hline 2001 & Earthquake & Peru & 145 & 349978 & 300 \\
\hline 2003 & Earthquake & Iran & 40000 & 710000 & 8000 \\
\hline 2005 & Earthquake & Iran & 612 & 94766 & 80 \\
\hline 2005 & Earthquake & Pakistan & 73338 & 5128309 & 5200 \\
\hline 2008 & Earthquake & China & 87476 & 45976596 & 85000 \\
\hline 2011 & Earthquake & New Zealand & 181 & 301500 & 15000 \\
\hline 2012 & Earthquake & Italy & 17 & 14350 & Not specified \\
\hline 2004 & Earthquake & Japan & 89 & 84792 & 2300 \\
\hline 2004 & Tsunami & Sumatra & 80 & 5063 & 500 \\
\hline 2010 & Tsunami & Chile & 562 & 2671556 & 30000 \\
\hline 2011 & Tsunami & Japan & 19846 & 368820 & 210000 \\
\hline 2004 & Tsunami & Indonesia & 165708 & 532898 & 4451.6 \\
\hline 1991 & Flood & China & 1729 & 210232227 & 7500 \\
\hline 1993 & Flood & China & 1000 & & 6061 \\
\hline 1993 & Flood & USA & 48 & 31000 & 12000 \\
\hline 1996 & Flood & China & 2775 & 154634000 & 12600 \\
\hline 1998 & Flood & China & 3656 & 238973000 & 30000 \\
\hline 1998 & Flood & North Korea & 50 & 10172 & Not specified \\
\hline 2002 & Flood & Europe & 167 & 49500 & 500 \\
\hline 2008 & Flood & USA & 24 & 11000148 & 10000 \\
\hline 2010 & Flood & Pakistan & 1985 & 20359496 & 9500 \\
\hline 2011 & Flood & Thailand & 813 & 9500000 & 40000 \\
\hline 2006 & Mudslides & Philippines & 1399 & 2562517 & 66.4 \\
\hline 2004 & Cyclone & USA & 10 & 30000 & 16000 \\
\hline
\end{tabular}

The second step is to develop the disaster severity assessment tool. The present study combines the DeBoer/Ferro classification models and customises the combination to suit its purpose. DeBoer [18] and Ferro [3] provide a model for classification of disasters from the medical perspective. Their model ranks the disasters based on scores associated to each value including Cause of disaster, National or International assistance, temporal, geographical and 
physical affected area, the number of fatalities and casualties, rescue time and severity of injuries (table 2).

This model has been further developed to accommodate the socio-economic factors of the affected community. The resulting Disaster Severity Assessment (DSA) framework is exhibited in table 3. The framework shares three characteristics with DeBoer/Ferro framework (time, fatality, casualty) and adds three new terms (financial damage, HDI and DRI). These terms are explained in the following section.

Table 2: The DeBoer/Ferro severity framework.

\begin{tabular}{|c|c|c|c|c|}
\hline Classification & Grade & Score & DeBoer & Ferro \\
\hline Cause & Natural/Man-made & $1 / 0$ & + & \\
\hline $\begin{array}{l}\text { Effect on surrounding } \\
\text { community } \\
\text { (National assistance/ } \\
\text { international assistance) }\end{array}$ & Simple/Compound & $1 / 2$ & + & \\
\hline Impact time & $>24$ hour $/ 1-24$ hour/ 1 hour $>$ & $2 / 1 / 0$ & + & + \\
\hline Radius of disaster area & $10 \mathrm{~km}</ 1-10 \mathrm{~km} /<1 \mathrm{~km}$ & $2 / 1 / 0$ & + & + \\
\hline Number Causalities & $\begin{array}{l}25-100 \text { causalities alive or dead } \\
\text { or } 10-50 \text { admission to hospital/ } \\
100-500 \text { causality or } 50-250 \\
\text { admission/more than } 500 \\
\text { causalities of more than } 250 \\
\text { hospital attendance }\end{array}$ & $0 / 1 / 2$ & + & \\
\hline $\begin{array}{l}\text { Rescue time (rescue first } \\
\text { aid }+ \text { transport }+ \\
\text { evacuation) }\end{array}$ & 24 hours $</ 6-24$ hours $</ 6$ hours & $2 / 1 / 0$ & + & + \\
\hline $\begin{array}{l}\text { Effect of infrastructure } \\
\text { (impact site + filter area) }\end{array}$ & Simple/compound & $1 / 2$ & & + \\
\hline Number of dead & $<100 / 100<$ & $0 / 1$ & & + \\
\hline Number of injured & $1000<100-999<100$ & $2<1<0$ & & + \\
\hline $\begin{array}{l}\text { Average severity of injuries } \\
\text { sustained }\end{array}$ & $2<1-2<1$ & $2<1<0$ & & + \\
\hline Total & \multicolumn{4}{|l|}{ 1-13 } \\
\hline
\end{tabular}

Each category is then defined by a number of thresholds starting from the minimum value observed in the disaster records (for example 1 day impact time) for the lower bound and ending to the upper bound where the outliners are observed (for example more than 2 weeks). The categories for impact time; fatalities, casualties, financial damage and severity are designed in a way that each category exhibits at least ten frequencies in the records. For the last two terms (HDI and DRI), the categories are identical with the thresholds used in their original reports $[12,13]$. The first characteristic is impact time associated with the number of days in which the disaster is in effect. The second characteristic is the damage to the population by either loss of lives (fatalities) or other types of damage to the population including injuries, etc. (casualties). The third characteristic is the 'relative financial damage' defined in this study as an indication of the material losses of the affected community. This characteristic originally is expressed in million dollars in various sources (NetCatService, EM-DAT). However 1 million dollar worth of damage in a low-income country 
such as India where the GDP/capita in 2005 was 740 dollar is likely to cause deeper socio-economical damage than a high-income country such as USA with 42,516 dollar GDP/capita in the same year. To that end the relative financial damage used in the DSA are calculated using the following formula (1):

$$
\text { Relative financial damage }=\frac{\text { Original damage of disaster }}{\text { Affected country GDP per Capita }}
$$

The result expresses the relative financial damage of a specific disaster in a specific year.

Table 3: Disaster severity assessment framework.

\begin{tabular}{|l|l|l|l|}
\hline Characteristics & Categories & Linguistic value & $\begin{array}{l}\text { Numeric } \\
\text { value }\end{array}$ \\
\hline Impact time (day) & $\begin{array}{l}\text { Over 2 weeks/between 1-2 weeks/ } \\
1 \text { day-1 week/1 day }\end{array}$ & $\begin{array}{l}\text { Extreme/long/ } \\
\text { medium/short }\end{array}$ & $3 / 2 / 1 / 0$ \\
\hline $\begin{array}{l}\text { Fatalities } \\
\text { (Person) }\end{array}$ & $\begin{array}{l}\text { Over 1000/between 100-999/ } \\
\text { under 99 }\end{array}$ & $\begin{array}{l}\text { High/medium/ } \\
\text { low }\end{array}$ & $2 / 1 / 0$ \\
\hline $\begin{array}{l}\text { Casualties } \\
\text { (Person) }\end{array}$ & $\begin{array}{l}\text { Over 1000, 000/between 1000, } \\
000-99,999 / \text { below 99,999 }\end{array}$ & $\begin{array}{l}\text { High/medium/ } \\
\text { low }\end{array}$ & $2 / 1 / 0$ \\
\hline $\begin{array}{l}\text { Relative financial } \\
\text { damage (USD) }\end{array}$ & $\begin{array}{l}\text { Over 10, 000/between 1000-10, 000/ } \\
\text { between 1000-100/under 100 }\end{array}$ & $\begin{array}{l}\text { Extreme/high/ } \\
\text { medium/low }\end{array}$ & $3 / 2 / 1 / 0$ \\
\hline HDI (\%) & $\begin{array}{l}\text { Under 4.66/ between 4.67 and } \\
6.40 / \text { between 6.41 and 7.59/over 7.59 }\end{array}$ & $\begin{array}{l}\text { Low/medium/ } \\
\text { high/extreme }\end{array}$ & $3 / 2 / 1 / 0$ \\
\hline DRI (\%) & $\begin{array}{l}\text { Under 3.65/between 3.66 and 5.72/ } \\
\text { Between 5.73-7.44/between 7.45 to } \\
10.58 / \text { tover 10.59 }\end{array}$ & $\begin{array}{l}\text { Low/medium/ } \\
\text { high/very high/ } \\
\text { extreme }\end{array}$ & $0 / 1 / 2 / 3 / 4$ \\
\hline Total Severity & $\begin{array}{l}\text { Less than 5/between 5 and 10/more } \\
\text { than 10 }\end{array}$ & \begin{tabular}{l} 
Severe/very severe/extreme \\
\hline
\end{tabular}
\end{tabular}

The last two categories indicate the capacity of the affected country for coping with disaster including the HDI and DRI. Human development Index [12] published by UNDP is based on health, education and living standards for each country. Where HDI is the lowest (such as Haiti), the country is less likely to have the capability to cope with the damages comparing to a county with higher HDI (such as Japan).

Table 4: The example of the DSA result.

\begin{tabular}{|c|c|c|c|c|c|c|c|}
\hline Severity & Disaster & 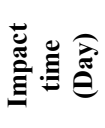 & $\frac{\hat{e}}{\hat{\theta}}$ & 품 & 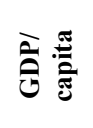 & 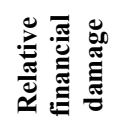 & 迥 \\
\hline \multirow{2}{*}{ Severe } & 2012 Italy earthquake & 1 & V & 112 & 33049 & 484.13 & 3 \\
\hline & 1982 Mexico eruption & 1 & $\mathrm{H}$ & 94 & 2366 & 49.45 & 5 \\
\hline \multirow{2}{*}{$\begin{array}{c}\text { Very } \\
\text { Severe }\end{array}$} & 1993 USA flood & 60 & $\mathrm{~V}$ & 127 & 25327 & 473.8 & 6 \\
\hline & 2004 Haiti cyclone & 2 & $\mathrm{~L}$ & 21 & 401 & 124.69 & 9 \\
\hline \multirow{2}{*}{ Extreme } & 2008 China earthquake & 1 & $\mathrm{M}$ & 78 & 3414 & 24897.48 & 12 \\
\hline & 1996 China flood & 27 & $\mathrm{M}$ & 78 & 703 & 17923.19 & 15 \\
\hline
\end{tabular}


Another characteristic is Disaster Risk Indicator (DRI), which calculates where the high exposure to natural hazards and climate change coincides with very vulnerable societies. This index is published in the World Risk Report [13]. Therefore where DRI percentage is higher, it is more likely that the affected society will fail to cope with the situation.

The present Disaster Severity Assessment (DSA) classifies disasters into 3 categories: severe disasters (less than 5 DSA rank), very severe disasters (rank between 5 and 10) and extremely severe disasters (Rank above 10). Due to publishing limitations, just an example of the results obtained from DSA technique is exhibited in table 4.

The significance of this framework is that it could be used as a quick guideline for decision makers under time pressures at the early stages of a disaster. By knowing the approximate number of fatalities, casualties and the financial damage, the disaster severity can be estimated at any given time and the response actions could be conducted accordingly. Also as the disaster develops, the numbers and the model can be easily re-adjusted. For a more technical decision maker that prefers to work with mathematical decision-making models, the DSA data could be used as the basis for building the fuzzy system's knowledge base to diagnose the severity of the situation in linguistic or numerical terms. An example of such system design is the subject of the next section.

\section{Fuzzy classification system}

According to Cintra et al. [19], classification is an important task in decisionmaking where it provides a key to the interpretation of the system's behaviour. But in some cases the parameters and input data are imprecise and the framework is required to adequately process the imprecise data as well as the associated uncertainty. To that end the fuzzy technique introduced by Zadeh [20] is selected for this study because of its capacity to classify the linguistic attributes associated to disaster situation. This classification is based on the rules drawn from a particular knowledge base, which in this paper are the result of the presented DSA in the previous section. The simplified steps of the fuzzy classification employed in the paper are described below:

1. Consider the pattern that requires to be classified (here it is the severity pattern of the disaster). The meaning of the linguistic terms is defined by their membership functions (2) where $\mathrm{S}$ stands for Severity. For example the membership function of the output (here Severity) is expressed in three linguistic terms including severe, very severe and extreme. A similar set of membership functions are required to be generated for each input (here including impact time, fatality, DRI, etc.).

$$
\mu_{s}: S \rightarrow[0,1]
$$

Therefore a simple presentation of this concept for severity is presented in figure 1 . 


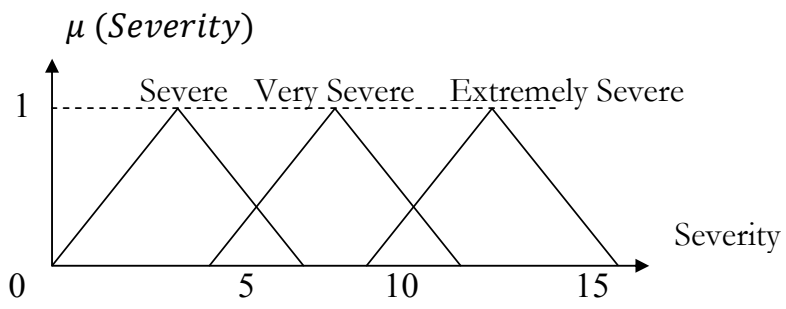

Figure 1: The graphic representation of the Severity membership function.

2. A set of fuzzy rules based on previous experience or expert opinion is defined to exhibit the relationships between inputs or terms (here the impact time, casualty,) and output (here severity). The rule base can be defined as $\{R i \mid i=1,2, n\}$, therefore the (semi) qualitative rule can be defined as (3):

$$
\text { if } x_{i 1} \text { is } A_{i 1} \text { and } x_{i 2} \text { is } A_{i 2}, \ldots, \text { and } x_{i n} \text { is } A_{i n} \text {, Then } y_{i 1} \text { is } B_{i 1}
$$

where $\mathrm{x}$ is the input (here impact time, fatality, direct), $\mathrm{y}$ is the output (here severity) and A and B is the linguistic variables such as high, low, extreme. Because in this model the impact time can take four values (Extreme/Long/Medium/Short), Fatality and casualties could each take three values (High, Medium, Low), Relative financial damage and HDI could take four values (Extreme, High, Medium, Low), DRI could take five values (Extreme, Very High, High, Medium, Low) and finally severity could take 3 values (Severe, Very Severe, Extremely Severe), The number of possible rules are 2160 rules $(4 \times 3 \times 3 \times 4 \times 5 \times 3)$. However the review of the DSA result in the previously recorded disasters (61 disasters) shows that the rules followed in reality can be summarised into the sum of 48 rules including the following examples.

Box 1: Rules derived from historical data.

Rule (1): if fatality is High and casualty is High and impact time is Extreme and HDI is Medium and DRI is Medium and financial damage is Very high then severity is Extreme.

Rule (48): if fatality is Low and casualty is Low and impact time is Medium and HDI is Very high and DRI is Very high and financial damage is Low then severity is Severe.

3. The fuzzy inference system runs the pattern through the rules to identify the class in which the output (severity) belongs. The compatibility of the rules then will be compared to the pattern of severity in disaster. The class predicted by the rule is assigned to the attributes. Figure 2 exhibits that how the severity of 
disaster can be diagnosed by identifying the conjunction between the imprecise variables' space. For enhancing the graphical illustration, assume a twodimensional pattern space $[0,1] \times[0,1]$ by having two variables of fatality and DRI. Based on the following simplified rules figure 2 can be illustrated as follows.

Box 2: Simplified rules for a two dimensional space.

If fatality is high and DRI is medium, then severity is extreme And

If fatality is low and DRI is low then severity is severe

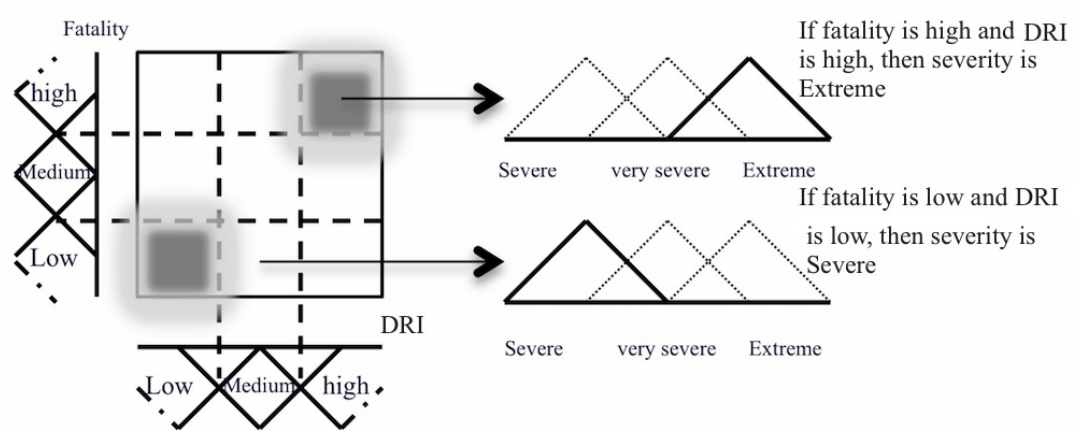

Figure 2: The overlapping areas of the fuzzy sets.

In a more complex space with more dimensions, if we have $\mathrm{K}$ fuzzy subsets $\left\{A_{1}^{k}, \ldots, A_{k}^{k}\right\}$, a triangular membership function [21] can be calculated based on formula (4) where (a) and (b) respectively are the upper and lower bound in each categories of input (table 1).

$$
\mu_{i}^{k}(x)=\max \left\{1-\left|x-a_{i}^{k}\right| b^{k}, 0\right\}, i=1,2, \ldots, k(k \geq 2)
$$

The formula (4) can be translated to the following if-then construct (5) in MSExcel to calculate $\mu(x)$ of the $x$-values (impact time, DRI, etc.) and $\mu(y)$ of the y-value (severity).

$$
\text { IF (AND (x > left, } x<\text { right), } 1 \text { - ABS ((left + right-2*x)/(right - left)), 0) }
$$

where left and right respectively represent the lower and upper bounds of the threshold (table 1) and ABS is the absolute value. Part of the result is exhibited in table 5 . 
Table 5: An example of the data used for triangular membership functions.

\begin{tabular}{|c|c|c|c|c|c|c|c|c|c|}
\hline \multicolumn{2}{|l|}{ Term } & Position & $x$-value & $\mu(x)$ & \multicolumn{2}{|l|}{ Term } & \multicolumn{3}{|c|}{ Position $x$-value $\mu(x)$} \\
\hline \multirow[t]{6}{*}{ Fatalities } & High & Left & 1000.00 & 0.00 & \multirow[t]{2}{*}{ HDI } & \multirow[t]{2}{*}{ Low } & Left & 0.00 & 0.00 \\
\hline & & Right & 10000000.00 & 0.00 & & & Right & 4.66 & 0.00 \\
\hline & Medium & Left & 100.00 & 0.00 & & \multirow[t]{2}{*}{ Medium } & Left & 4.67 & 0.00 \\
\hline & \multirow{3}{*}{ Low } & Right & 999.00 & 0.00 & & & Right & 6.40 & 0.93 \\
\hline & & Left & 0.00 & 0.00 & & \multirow[t]{2}{*}{ High } & Left & 6.41 & 0.00 \\
\hline & & Right & 99.00 & 0.00 & & & Right & 7.58 & 0.28 \\
\hline \multirow[t]{6}{*}{ Severity } & Severe & Left & 0.00 & 0.00 & & \multirow[t]{6}{*}{ Extreme } & Left & 7.59 & 0.27 \\
\hline & \multirow{3}{*}{ Very Severe } & Right & 5.00 & 0.00 & & & \multirow[t]{5}{*}{ Right } & \multirow[t]{5}{*}{100.00} & 0.00 \\
\hline & & Left & 5.00 & 0.00 & & & & & \\
\hline & & Right & 10.00 & 0.00 & & & & & \\
\hline & \multirow[t]{2}{*}{ Extreme } & Left & 10.00 & 0.00 & & & & & \\
\hline & & Right & 20.00 & 0.00 & & & & & \\
\hline
\end{tabular}

The data provided in table 5 and the two simplified rules employed in figure 2 were used for simulation and control of the model with an open source computer program (Fuzzylite, 2013) as is exhibited in (figure 3).

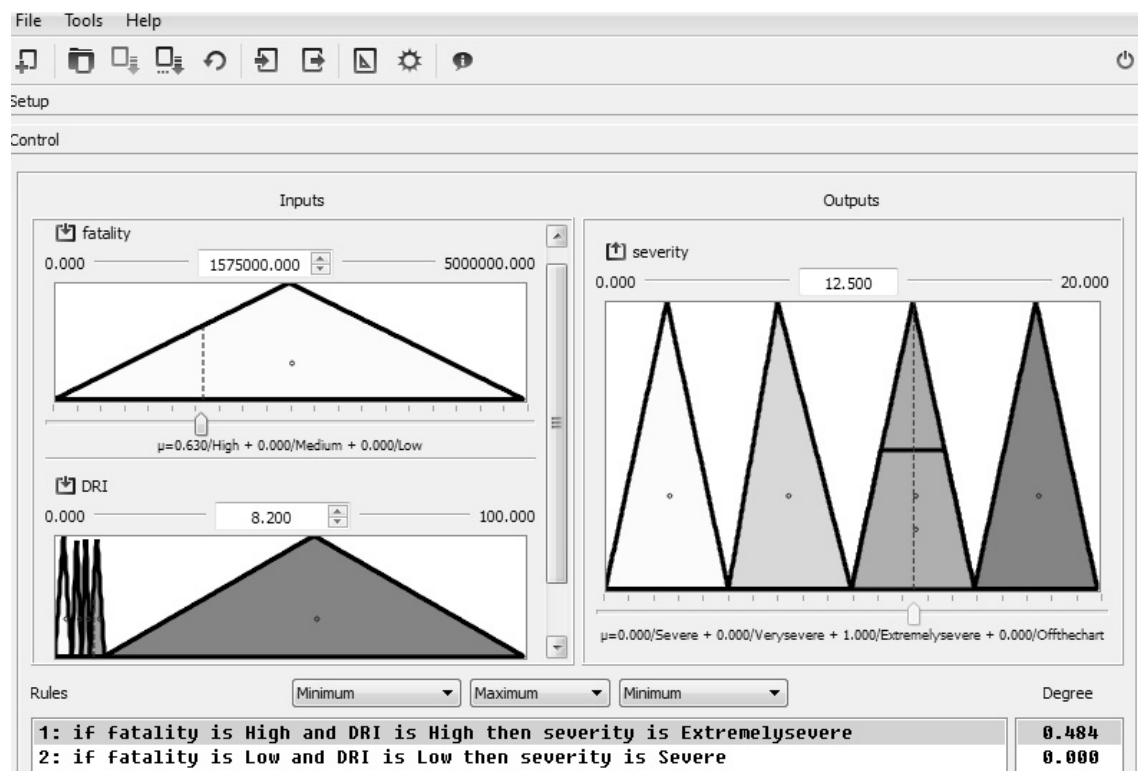

Figure 3: A snapshot of the created fuzzy model based on the data in table 3 .

Figure 3 employs the clipping as one of the most common ways of showing correlation between the rule outputs with the truth-value of the rule input [22]. It basically cuts the output membership function at the level of the input truth. Slicing the top of the membership function leads to the loss of part of the 
information in fuzzy set. In the above example the graphs show that where the fatality is equal to $1,575,000$ persons (high) and DRI is $8.2 \%$ (high), the severity is 12.5 (extremely severe) when the rule 1 is activated with 0.484 degrees of strength. This principle can apply to any possible values of the outputs and inputs.

\section{Conclusions}

This paper is an attempt to classify the possible scenarios of disaster impact in order to diagnose the severity of the disaster in its early stages of development where information is most scarce. In this situation the decisions need to be made under time pressures and with the minimum amount of primary data. Therefore a decision support tool is required to quickly diagnose the severity of the situation based on the data available. To that end in this paper a decision support tool is designed targeting two groups of decision makers. The first tool (DSA) is a simple framework based on previous disasters and the socio-economic characteristics of the affected community. It is constructed from a simple chart that can be used by any decision maker without mathematical background. Another significance of this framework is that its linguistic values and boundaries could be altered according to the situation. It enables the decision makers to narrow the various classes of severity and estimate the severity of the situation with more precision if required. The paper also explains the preliminary steps to simulate the DSA in a fuzzy classification system which can be used by a more technical decision maker and accommodate imprecise values and map the disaster severity. The result could assist the decision makers to more accurately address and diagnose the severity of the situation and reduce the risk of failure in disaster response operation. The study also faces the issue of data limitations. First the data from various sources show discrepancies. In many cases the data provided in the Munich RE and EM-DAT databases and the NetCatService database report different statistics. Although this weakness is partially addressed by the use of fuzzy logic, which is designed for imprecise data, it is noteworthy to remember the inconsistency of the reported data. Also the processed data is drawn from 61 natural disasters with the most destructive magnitudes. Although these amounts of data are sufficient for statistical interpretation, more data needs to be processed for building a rich knowledge base for defining fuzzy rules. The data also excludes man-made disasters. However the results to some extent are extrapolatable to any types of disasters. This study is part of an extensive ongoing research, which attempts to reduce the risk of failure in humanitarian response networks by developing a scenario-based decision framework for disaster partner configuration.

\section{References}

[1] Rutherford, W.H. \& De Boer, J., The definition and classification of disasters", Injury: British Journal of Accident Surgery, 15(1), pp. 10-12, 1982. 
[2] Gad-el-Hak, M., Large-Scale Disasters: Prediction, Control and Mitigation, Cambridge University Press: London, 2007.

[3] Ferro, G., Assessment of major and minor events that occurred in Italy during the last century using a disaster severity scale score, Pre-Hospital and Disaster Medicine, 20 (5), pp. 316-23, 2005.

[4] Carr, L.J., Disaster and the sequence-pattern concept of social change, American Journal of Sociology, 38 (2), pp. 207-218, 1932.

[5] Barton, A., and Communities in disaster: A sociological analysis of collective stress. Doubleday: Garden City, NY, 1969.

[6] Britton, N.R, Developing an understanding of disaster. Australia \& New Zealand Journal of Sociology, 22(2), pp. 265-271, 1986.

[7] Rongier, C., Gourc, D., Lauras, M. \& Galasso, F., Towards a Performance Measurement System to Control Disaster Response, Collaborative Networks for a Sustainable World in IFIP Advances in Information and Communication Technology, 336, pp. 189-196, 2010.

[8] Wickramaratne, S., Ruwanpura, J., Ranasinghe, U, Walawe-Durage, S, Adikariwattage, V, Wirasinghe, S., Ranking of natural disasters in Sri Lanka for mitigation planning. , 3(2), pp. 115-132, 2012.

[9] Mishra, V., Fuloria, S. \& Bisht, S.S., Enhancing disaster management by mapping disaster proneness and preparedness. Disasters, 36(3), pp. 38297, 2012.

[10] Berren, M., Beigel, A. \& Barker, A typology for the classification of disasters: Implications for intervention, Community Mental Health Journal, 18(2), pp. 120-134, 1982.

[11] Eßig, M. \& Tandler, S., Disaster Response Supply Chain Management (SCM): Integration of Humanitarian and Defence Logistics by Means of, SCM, in Walter Feichtinger, Markus Gauster, Fred Tanner (eds.). Economic Impacts of Crisis Response Operations - An Underestimated Factor in External Engagement, Austria: Institut für Friedenssicherung und Konfliktmanagement (IFK), pp. 283-310, 2010.

[12] Human Development Reports (HDR), United Nations Development Programme (UNDP) online, http://hdr.undp.org/en/statistics/

[13] World Risk Report 2012, online http://www.worldriskreport.com/uploads/ media/WRR_2012_en_online.pdf

[14] Gunn, A., Encyclopaedia of Disasters Environmental Catastrophes and Human Tragedies, Greenwood: Connecticut.

[15] Significance natural disasters since 1980, Munich, reinsurance company, Online, http://www.munichre.com/en/reinsurance/business/non-life/geo risks/natcatservice/significant_natural_catastrophes.aspx

[16] The international disaster data base (EM-Dat), The Centre for Research on the Epidemiology of Disasters (CRED), online http://www.emdat.be

[17] Inventory system of the effects of disasters (DesInventar), Online http://www.desinventar.org/en/database

[18] De Boer, J., Definition and classification of disasters: introduction of a disaster severity scale, The Journal of Emergency Medicine, 8, pp. 591-5, 1990. 
[19] Cintra, E. Estevam, H. Hruschka R. and Nicoletti, M., Automatic Construction of Fuzzy Rule Bases: a further Investigation into two Alternative Inductive Approaches. Journal of Universal Computer Science, 14(15), pp. 2456-2470, 2008.

[20] Zadeh, L. A., Fuzzy Sets. Journal of Information and Control, 8, pp. 338-353, 1965.

[21] Ishibuchi, H., Nozaki, K., Yamamoto, N. and Tanaka, H. Construction of fuzzy classification systems with rectangular fuzzy rules using genetic algorithms. Fuzzy Sets and Systems, 65, pp. 237-253, 1994.

[22] Negnevitsky, M. Artificial intelligence. Harlow, England: AddisonWesley, 2005. 